\title{
Bajo el signo de un dios salvaje: escenarios contemporáneos del superhéroe
}

\author{
Ivan Pintor Iranzo"
}

Universitat Pompeu Fabra, España

Recibido: 24 de junio 2019; aceptado: 9 de julio 2019

\begin{abstract}
Resumen
Más allá de su dimensión mitológica, las adaptaciones cinematográficas de los superhéroes Marvel ofrecen una completa pedagogía acerca de las concepciones contemporáneas sobre la relación entre cuerpo, tecnología y mutación. A lo largo de la historia del cómic de superhéroes, la transformación del mito ha evolucionado a través del desdoblamiento original del héroe, la necesidad de mantener doble identidad y la mutación hacia espacios narrativos vinculados, por una parte a lo onírico y por otra hacia un campo de tensión filosófica entre el transhumanismo y lo posthumano. El presente artículo realiza un recorrido histórico y conceptual a través del arquetipo superheroico para hacer hincapié en el ensamblaje entre las posibilidades del cómic y las del cine. Tanto las singularidades contemporáneas del mutante, por una parte, como los acercamientos heterodoxos al superhéroe por parte del cineasta Manoj Night Shyamalan constituyen una indagación filosófica, ética y mitológica de los dispositivos políticos, sociales y perceptivos que acompañan el legado de esta tradición nacida al mismo tiempo que el cómic de aventuras de los años treinta.
\end{abstract}

Palabras Clave: Superhéroe | Mutante | Marvel Universe | DC Comics | Posthumano

Under the sign of a wild god: contemporary scenarios of the superhero

\begin{abstract}
Beyond their mythological dimension, the contemporary movie adaptations of the Marvel superheroes universe offer a pedagogy about the technological relationship between body and mutation. Throughout the history of the superhero comic-book, the myth has evolved from the original unfolding of the hero, double identity and mutation towards narratives related to the oneiric and also to a field of philosophical tension between transhumanism and the posthuman. This article takes a historical and conceptual journey through the superhero archetype to emphasize the assembly between the possibilities of comics and the cinema. Both the contemporary singularities of the mutant, on the one hand, and the unorthodox approaches to the superhero by the filmmaker Manoj Night Shyamalan constitute a philosophical, ethical and mythological investigation of the political, social and perceptive devices that accompany the legacy of this tradition born at the same time that the adventurous comic-strips of the thirties.
\end{abstract}

Key Words: Superhero | Mutant | Marvel Universe | DC Comics | Posthuman

En uno de los textos compilados en el volumen $E l$ hacedor (1960), titulado Ragnarök, Jorge Luis Borges relata una escena de pesadilla, que prologa con una alusión a la teoría romántica de los sueños de Samuel Taylor Coleridge. Al atardecer, en el Aula Magna de la Facultad de Filosofía y Letras, el narrador describe la llegada de un pequeño grupo de individuos entre aplausos y aclamaciones de la concurrencia, que grita “ $¡$ Ahi vienen!" y después “¡Los Dioses! ¡Los Dioses!”. Mientras sus siluetas se encumbran en la tarima, cunde con horror la sospecha de que los Dioses, algunos con forma humana y otros con atributos animales, hayan perdido el habla, después de siglos de vida fugitiva y feral. Nada en ellos parece recordar el brillo del pasado, y sus frentes bajas y sus dentaduras podridas quedan enmarcadas por ropas vulgares y navajas de facineroso. Con la certidumbre soñada de que se han vuelto tan ignorantes como crueles y peligrosos, que la única salida es sacrificarlos antes de que destruyan a la humanidad, la voz narrativa de Borges concluye "Sacamos los pesados revólveres (de pronto hubo revólveres en el sueño) y alegremente dimos muerte a los Dioses".

Con la atención hacia la mutación de las formas que el sueño siempre insufla en la literatura de Borges, la escena atestigua el carácter mercurial de los héroes, que atraviesan la historia de la literatura, el cómic y el cine dejando

* ivan.pintor@upf.edu 
la estela de sus nombres. Acaso en el cómic, después de siglos de vagabundear, de camuflarse con máscaras diversas y de asomarse incluso a la Edad Contemporánea a través la poesía romántica alemana y el simbolismo francés, los dioses paganos encontraron un lugar en el que poder empezar de nuevo, en el que poder acompañarse de una liturgia capaz de hacer de su figura una aparición, una revelación dispuesta a hacer partícipe al testigo, al lector. La reconvención que un joven le hiciera a Baudelaire (Calasso, 2006) señalando, una mañana de 1851 y en el aniversario de la Revolución de 1848, que el Dios Pan, a pesar de todo, no había muerto, es la idea que preside, desde sus inicios, el mundo de los superhéroes de cómic, en particular el universo Marvel y su constelación de mutantes y figuras mitológicas y semi-animales surgidas al calor de la Guerra Fría en Estados Unidos.

Como han señalado James Hillman (2016) y Peter Kingsley (2008, 2017), a la sombra de las columnas resplandecientes del Partenón no sólo es posible buscar patrones de belleza formal o el origen del monoteísmo de la psique consciente que caracteriza la filosofía occidental, sino también una iluminación psicológica que se derramaba en la vida cotidiana griega más allá de los santuarios de Delfos y Eleusis. Para Hillman, frente al legado heroico del hebraísmo, la multiplicidad de dioses del paganismo antiguo proporciona un modelo de integración desintegrada adecuado a la pluralidad de imágenes que disgregan la psique contemporánea. Cabalgando sobre los espejismos de la pesadilla, ese modelo complejo, señala Hillman, regresa en el mundo moderno con la silueta del dios Pan y los múltiples avatares de su figura esbelta, de patas hirsutas y cabeza coronada por gráciles cuernos, que pueden ser reconocidos en los superhéroes y su capacidad para reencantar el suelo, tantas veces baldío, de los siglos XX y XXI.

Tomando como punto de partida la escena ensoñada del asesinato de los Dioses, transformados en figuras vanas y fútiles, carentes de lenguaje y alienadas de su condición justiciera y benévola, es posible volver las miras sobre el trayecto histórico-mediático de la representación del superhéroe. No hay una gran diferencia entre la escena descrita por Borges en su relato y algunas de las secuencias que atraviesan los cómics escritos por guionistas como Alan Moore, Grant Morrison o Frank Miller desde mediados de los años ochenta del siglo XX. Con obras como Batman, el señor de la noche (Batman Dark Knight, 1986), de Frank Miller, Janson y Varley, Watchmen (1986), de Alan Moore y Dave Gibbons, Elektra Assassin (1986), de Miller y Sienkiewicz, y Animal Man
(1988-1990), de Grant Morrison, la figura del superhéroe cerró, en el arco de cinco décadas, un ciclo semejante al que la historia de la mitología había deparado a los dioses en su secular infiltración literaria. El asesinato de Edward Blake, El Comediante, en Watchmen, la imagen de Superman consumiéndose en Batman, el señor de la noche o el via crucis al que es sometida Elektra rubrican con la misma fuerza perturbadora que el sueño de Borges ese itinerario heroico.

Numerosas preguntas cundieron en los años ochenta ante la obsesión por representar la decrepitud y la muerte de los superhéroes así como la dificultad de sostener su pacto ficcional: ¿Qué grado de verosimilitud pueden seguir teniendo figuras enfundadas en mallas y capas de colores, dotadas de poderes sobrehumanos, que surcan los cielos del planeta para impartir justicia en un mundo tan cínico como el que, en el ámbito anglosajón abrieron los mandatos de Ronald Reagan en Estados Unidos y Margaret Thatcher en el Reino Unido? ¿Cuál sería hoy el estatuto político y aún jurídico de superhéroes y mutantes? , e incluso ¿Quién vigila - como abre Moore en una cita manifiesta de Juvenal-, a los vigilantes? Frente a esos interrogantes, que sellaban un trayecto de inscripción en la cultura popular en el que la idea proyectiva del monomito heroico (Campbell, 1959, 2018) había ido dando lugar a una enorme plasticidad para la representación política y social, tanto el espacio del cine Marvel de las últimas dos décadas como la serialidad televisiva contemporánea - Daredevil (Netflix, 2015), Jessica Jones (Netflix, 2015-2019), Luke Cage (Netflix: 2016-2018), Legion (FX: 2017), Agents of Shield (ABC: 2013-2019), The Punisher (Netflix: 2017-2019), Iron Fist (Netflix: 2017-2019) -, abren un interrogante aún más profundo sobre el lugar narrativo, mitológico, político y ético del superhéroe. ¿Bajo qué formas se actualiza la potencia mitopoética del superhéroe en el universo expandido de la Marvel y la DC contemporáneas? ¿Cómo se han reasociado ciertas constantes iconográficas del superhéroe con las nuevas cuestiones políticas que urgen a la sociedad contemporánea?

\section{Desdoblamiento y doble identidad del héroe}

En muchos sentidos, el universo de los superhéroes nace, como el del western, con la necesidad de afianzar el paisaje mitológico de una tierra nueva, de un nuevo Edén, los Estados Unidos, caracterizado tanto por la ética de conquista como por una fórmula religiosa que 
combina el rigor protestante con el icono trascendental del Cristo resucitado (Bloom, 1994), y no la con lógica sacrificial de la pasión que acompaña su figura crucificada en el orbe católico. No es casual que el teórico del cómic Gino Frezza, en La máquina del mito en el cine y el cómic (2017), lea como primer paso en la construcción del superhéroe clásico el episodio inicial de un pulp escrito por Edgar Rice Burroughs, John Carter de Marte $(1912)^{1}$, un héroe de la pradera norteamericana que sufre un accidente en el interior de una cueva y ve su cuerpo desdoblado: una de las dos partes queda en tierra como vestigium ${ }^{2}$ de su nueva imagen, y la otra acaba en Marte. Con ello tanto el problema de la mortalidad del héroe como, de un modo más amplio, la relación entre

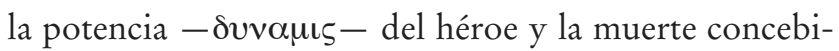
da como impotencia queda solventado, soslayado en ese pasado totalmente enterrado.

Una segunda fase en la construcción del arquetipo concentra la vulnerabilidad en una personalidad cotidiana y anodina como la de Clark Kent, el alter ego de Superman, creado por Jerry Siegel y Joe Schuster en 1934. Hay, en el patrón mesiánico de Superman, enviado desde un planeta lejano por su padre, un alejamiento del primer paradigma del héroe surgido del western, y una simultánea afirmación de su condición metropolitana. Una legión de personajes disfrazados con capas y másca$\mathrm{ra}-\mathrm{a}$ los que los editores llamaban "personajes con ropa interior larga” - aparecieron en los quioscos antes del final de la $\mathrm{II}^{\mathrm{a}}$ Guerra Mundial, la mayor parte de ellos de la oficina del editor William Gaines. En el plazo de unos pocos años, sus empleados producían de manera serial personajes como Flash, Green Lantern, Hawkman, Hourman y varias decenas más, la mayor parte de ellos con una cierta similitud con Superman. Sin embargo con el final de la década de los treinta coincidieron tres fenómenos que introdujeron una variación sensible tanto en la construcción arquetípica del héroe como de su infiltración en las narrativas sociales: el éxito de un justiciero nocturno como Batman, la aparición de la superheroína Wonder Woman y la mutación de la serialidad en torno a la idea del supergrupo.

Por una parte, con la publicación de la historieta "El caso del sindicato químico", desarrollada por Bill Finger y Bob Kane, en la revista Detective Comics n ${ }^{\circ} 27$ el 30 de marzo de 1939 asomaban entre las viñetas las largas orejas la silueta de Batman, un personaje nocturno, lunar, como lo fueran tantos vengadores enmascarados de finales de los años treinta y de los años cuarenta, comenzando por The Shadow - nacido como serial radiofónico en 1930 de la mano de Maxwell Grant (Walter B. Gibson), con la voz de Orson Welles y dibujado por autores como Vernon Greene o Frank Robbins - y siguiendo por The Spirit (1940) o Lady Luck (1940-1946), de Will Eisner, y The Phantom (1936), de Lee Falk y Ray Moore. El trauma fundacional que transforma a Batman en héroe, el asesinato de sus padres, hizo que la enorme fortuna familiar heredada le sirviese para proveerse con todo tipo de ingenios y prótesis en su lucha contra el crimen y el mantenimiento del statu $q u o$. Si los años treinta mostraban el tejido de continuidad entre los pulp, el género de western, los aventureros de primera generación -Flash Gordon (1934), de Alex Raymond, Buck Rogers (1933), de Phil Nowlan y Dick Calkins - y Superman, los años cuarenta constituyen el espacio de una figura dúctil, sin superpoder alguno, que se confunde con los ambientes lumpen entre los que se mueve, a imagen y semejanza del icónico justiciero Dick Tracy (1931-1977), de Chester Gould.

Si bien, en términos generales tres superhéroes como Superman, Batman y Spiderman constituyen los modelos respectivos otras tantas variaciones arquetípicas fundadas en la multiplicación de los poderes, el desdoblamiento y la hibridación metafórica con un animal, Gino Frezza (2017) señala existencia de una clara evolución desde el desdoblamiento que deja la muerte atrás hacia la neurosis que provoca la coexistencia con el doble anónimo y vulnerable -Clark Kent, Bruce Wayne-. En última instancia, el superhéroe está destinado a vivir en una honda intimación con la muerte, como sucede a partir de los años ochenta. Toda la historia y las variaciones en la construcción ética del superhéroe podrían leerse a partir de la figura de Batman, cuyo motor último es la venganza. El imperativo ético de la acción, que convierte la ejecución en el paradigma de un castigo carente de cualquier dispositivo de justicia, hace de Batman un modelo de héroe especialmente dúctil. No hay que olvidar que el primer Batman era, a imagen y semejanza de Dick Tracy, un personaje de una violencia extrema, capaz de romper a propósito el cuello de un hombre, de matar a un delincuente menor -"The Batman. The Return of Dr. Death", Detective Comics n ${ }^{\circ} 30$, agosto de 1939- o de carecer, como los héroes del escritor Mickey Spillane, guionista de algunas entregas, de aparente empatía.

\section{Superheroínas y supergrupos}

La idea, formulada por el historietista Art Spiegelman al referirse a Dick Tracyde Chester Gould, según la 
cual dibujar cómics no consiste nunca en la mera tarea de ilustrar una historia, sino en crear "diagramas narrativos" (Pintor, 2017) hace que los villanos de Dick Tracy y Batman -Joker, el Pingüino, Riddler, Two-Face, en este último caso, y Corpse, Redrum, Pruneface, Flattop en Dick Tracy - resulte terrorífica, y en muchos sentidos imposible de trasladar a la imagen cinematográfica, pues cada uno de los caracteres constituye prácticamente un signo gráfico. De naturaleza opuesta es Wonder Woman, que encarnaba sus rasgos en la mitología clásica, como también lo haría años después la compañía Marvel con Thor. Fue creada por William Moulton Marston, que firmó con el seudónimo Charles Moulton las aventuras de una heroína concebida inicialmente a partir del arquetipo de Diana y con el propósito de ganar lectoras. Moulton Marston, investigador y creador también del test de presión sistólica, esto es la conocida como "máquina de la verdad", dotó a Wonder Woman de una serie de atributos como un avión telepático, unos brazaletes que desvían las balas o, sobre todo un lazo místico que obliga a todo aquel que se encuentra atrapado en él a decir la verdad.

Wonder Woman, cuya ética no se fundaba en ningún caso en la mera razón de la fuerza, abrió un espacio ético apartado de la punición e idea de sheriff que amparaba el resto de justicieros. En su perfil domina la idea que tanto Campbell, como Propp o Durand denominan "héroe atador", caracterizada por el ejercicio de una inteligencia que se antepone a la fuerza. Precisamente ese contraste es el que favoreció que, en 1941, los escritores John Broome y Gardner Fox, que reunieron en grupo a una serie de héroes bajo el nombre The Justice Society of America decidieran incorporar a Wonder Woman como uno de sus ejes fundamentales. Y, si bien en los años cincuenta, con las heridas de la Guerra Mundial todavía abiertas, el war-horror y el melodrama desplazaron el éxito de los superhéroes, fue en 1956 cuando Julius Schwartz, de Detective Comics (DC) intentó resucitar a un personaje, Flash, al tiempo que hacía lo mismo con Green Lantern, Hawkman, The Atom, Hourman, Black Canary, y la Justice Society, rebautizada con el nombre de The Justice League of America.

Al tiempo que Schwartz no sólo se dedicaba a reflotar superhéroes sino que, junto al guionista Bob Kanigher y el dibujante Carmine Infantino incorporaba como subterfugio la multiplicación de dimensiones paralelas para justificar desavenencias entre las tramas del pasado y las contemporáneas (Morrison, 2011), la compañía rival de DC, Timely, que poseía personajes tan singulares como
Submariner, The Human Torch y Captain América, relegó la producción de westerns, cómics humorísticos y terror para gestar un supergrupo que está en la génesis de los códigos bajo los cuales los largometrajes Marvel contemporáneos se han convertido en verdaderos corpus teóricos sobre la experiencia de lo posthumano (Jeffery, 2016). Lee le pidió al dibujante Jack Kirby que se encargase del proyecto y juntos crearon Los cuatro fantásticos(The Fantastic Four, 1961). Dos elementos nuevos en los comics distinguieron a la colaboración de Lee y Kirby desde el principio. El primero era la ausencia de disfraces, sustituidos por monos y el segundo, de un modo mucho más relevante, fue construirlos como personajes humanos, irascibles, malhumorados y con problemas de integración.

Mientras Timely cambiaba su nombre por el de Marvel, Los Cuatro Fantásticos, cuyo antagonista inicial era el Dr. Doom, vivían como una familia, y debían sus poderes a los efectos de las radiaciones cósmicas durante un viaje espacial. Mr. Fantastic - Reed Richards-, que puede estirar desmesuradamente todos sus miembros, como su precedente Plastic Man (1941) -creado por Jack Cole-, su pareja, La chica invisible -Sue Storm-, hermana de Johnny, La antorcha humana, que entra en ignición a voluntad, y La Cosa - Ben Grimm-, que se transforma en una masa pétrea, constituyen una traslación de los cuatro elementos de la mayor parte de cosmogonías tradicionales, aire, agua, tierra y fuego, casi como proyecciones de la poética material de los elementos desarrollada filósofo Gaston Bachelard (1938, 1942, 1943, 1948a, 1948b). En muchos sentidos, la exposición pública de los cuatro miembros del supergrupo, que no vivían ocultando una doble identidad, pudo y podría releerse como una sutil somatización del trauma de los supervivientes a la experiencia de la II ${ }^{a}$ Guerra Mundial, y en particular de los campos de concentración, convertido en el estigma y la superioridad del mutante. El hecho de que tengan su reverso en otros tantos personajes de poderes descontrolados, la familia real de Los Inhumanos, que habita un espacio paralelo llamado La Zona Negativa, reafirma ese poso de negatividad traumática en los personajes ${ }^{3}$.

\section{Teratologías y mutaciones: contrafiguras del progreso}

A causa de la fascinación del cosmos heroico creado por Lee y Kirby a partir de ese momento emerge de 
un equilibrio entre la psicología realista de los personajes y un uso de arquetipos que añade entre sus filas una pléyade de divinidades de las más diversas procedencias: Cíclope, Fénix o Coloso, que no requieren siquiera explicación, pues llevan el nombre de sus referentes arquetípicos, encarnaciones del Quirón mítico -Ojo de halcón-, silenos sabios y ancianos - Dr. Xavier-, sátiros - Rondador nocturno (Nigh Crawler) -, titanes -Coloso-, cíclopes - Cíclope-, ninfas - Pícara (Rogue) $-{ }^{4}$. A todas estas criaturas, bien arraigadas en la tradición grecolatina, se les añaden dioses nórdicos - Thor, Loki- y héroes ligados a las fuerzas primordiales de otras culturas, como Tormenta (Storm), de los $\mathrm{X}-\mathrm{Men}$, con poder sobre el clima y del encuentro entre la deidad africana Yemanyá ${ }^{5}$ y los Shedhim o demonios de la tormenta de la mitología judeocristiana.

Por otra parte, y en este aspecto reside uno de los rasgos más relevantes de la interferencia entre historieta y mitología, estos personajes se caracterizan por su extrema plasticidad para la transformación. Tal y como facilita la proyección imaginaria del lector a través del intervalo, del blanco intericónico que separa las viñetas, el cómic es un medio que facilita la hibridación entre figuras, una disposición hacia la imaginación agente y abierta (Pintor, 2015a, 2015b, 2018). Tal vez por eso, abundan en el cómic los seres teriomorfos ${ }^{6}$, hibridados, humanos con el poder de diferentes bestias. Así, Escarabajo, Unicornio, el Hombre Rinoceronte, Dr. Octopus, El Lagarto, Anaconda, Boa, Constrictor, Iguana, Gata Negra, Puma o Chaqueta Amarilla ${ }^{7}$ son algunos de los personajes antagonistas que reaparecen en diversas series. El grifo ${ }^{8}$, una suma de animales terribles, encarna la amenaza por antonomasia, y Hobgoblin, el Duende Verde, puede integrarse en la misma nómina. En muchos sentidos, esas figuraciones deben verse, por su participación arquetípica en cauces representacionales tradicionales, en el espacio de transmisión figurativa de los animales-símbolo en las culturas tradicionales, en el sentido con que los ha estudiado Marius Schneider (1998).

Los hallazgos de Schneider en el terreno de la pervivencia de estructuras totemísticas y megalíticas de las altas culturas en el folklore español establecen, además, correlaciones singularmente atentas a la dimensión rítmica, melódica y en términos generales musical de las representaciones animales. No sólo porque el cómic se atenga, ante todo a fenómenos de rimo, ritma y cadencia en la percepción de la panopsis (Pintor, 2017) sino incluso porque el alba de los superhéroes híbridos coincide con una transformación del espacio cultural del pop y el rock en Estados Unidos, personajes como los mencionados configuran un elenco proyectivo destinado al lector adolescente moldeable con el universo de las estrellas musicales. En esa proximidad entre la rock-star y lo animal reside la ambigüedad de algunos personajes a priori heroicos y positivos como Spiderman, que en ocasiones destacan por su relatividad moral o por haberse dejado poseer por su lado negativo. Es, en particular en torno a Spiderman donde se abre un contrato narrativo diferente, tanto por su capacidad de vehicular el retrato de problemas sociales reales, como la drogadicción, la segregación racial o la pérdida de un ser amado - con la muerte dramática del personaje de Gwen Stacy, la novia de Spiderman, en Amazing Spider-Man \#121 (Conway, Kane, Romita Sr, Mortellaro \& Hunt, 1973)-.

Cualquier evento acaecido en las diferentes colecciones de Marvel empezó ya en la década de los setenta, a afectar al resto de universos narrativos, en un tejido de argumentos cruzados mucho más denso que el de la DC, organizado en torno a una estructura escatológica, esto es, con hechos apocalípticos cíclicos capaces de vertebrar y renovar la temporalidad que habitan los personajes, algo que refrenda el paralelismo con la naturaleza arquetípico-religiosa de los animales en las culturas tradicionales descrita a partir de la obra de Schneider. Esa escatología, que la serialidad del siglo XXI ha sabido recuperar - Heroes (NBC: 2006-2010), Alias (ABC: 20012006), Perdidos(Lost, ABC: 2004-2010), Fringe (Fox: 2008-2013), The Leftovers (HBO: 2014-2017)-, empezó a enriquecer el grupo de personajes mitológicos mencionados, con sacerdotes y chamanes - Dr. Strange-, un sistema policial -SHIELD (Supreme Headquarters International Law Enforcement Division), al frente del cual se situaba Nick Fury, personaje que había nacido como un duro sargento del ejército durante la guerra-, e incluso mesías cósmicos como Estela plateada (Silver Surfer) y toda una cohorte de arcontes y divinidades hambrientas y temibles - The Watcher, Galactus ${ }^{9]}-$.

Sin embargo, fue sobre todo la serie $X-M e n$ (1963) la que posibilitó una experimentación narrativa mayor en el terreno de la construcción ético-política de la figura capital sobre la que se erige el destino de Marvel como factoría de entretenimiento y de reflexión sobre el cuerpo y la condición humana en el audiovisual contemporáneo: el mutante. De la mano de Stan Lee y Jack Kirby primero, y Roy Thomas, Werner Roth, Neal Adams y, sobre todo Chris Claremont junto a una serie de dibujantes como John Byrne, Jim Lee, Dave Cockrum, John Romita Jr., Silvestri y Barry Windsor-Smith, X-Men ges- 
tó un campo de tensión donde la figura del mutante no sólo se convirtió, como en el caso de Los cuatro fantásticos, en una plausible relectura de las huellas de los supervivientes de la $\mathrm{II}^{\mathrm{a}}$ Guerra Mundial, sino también en una manifestación de la irredimible soledad del individuo contemporáneo, en el seno de una suma de fracturas que releen lo que la literatura había explorado en el cambio del siglo XIX al XX, lo que Claudio Magris (1993) definiera como el testimonio de la "odisea de un engaño".

La nostalgia de la forma épica por excelencia, la del individuo que viaja para conseguir algo o batir a un enemigo, se encuentra con un imaginario marcado por la privación de rasgos específicos de los protagonistas de la literatura de Musil, del Joseph K de Kafka o el Peter Kein de la novela Auto de fe (Die Blendung, 1935), de Elías Canetti, seres atrapados por el tiempo, que no saben vivir y a quienes no les queda ya nada por descubrir, sometidos por un entorno que los supera de forma permanente, como ha señalado Northrop Frye (1977). A pesar de que pueda invocar lo contrario, la mutación, como condición diferencial extrema se manifiesta en un estado de separación y pérdida perenne, tanto de la naturaleza como de la cultura, para el cual el supergrupo es sólo un pálido lenitivo. Si, como ha indicado el antropólogo mexicano Roger Bartra al analizar la pervivencia de la figura del salvaje europeo en la iconografía occidental (Bartra, 1996, 1997), de los silvos y faunos clásicos a San Jerónimo y las Magdalenas penitentes, el mito del progreso exige la contrafigura de un vínculo con la naturaleza, personajes con una acentuación de los rasgos animales que, posibiliten, como por su parte ha explorado el filósofo italiano Giorgio Agamben (2006), un espejo para el reconocimiento de lo humano.

\section{La melancolía del salvaje}

Dos son los personajes Marvel que mejor encarnan la idea del salvaje: La bestia y, sobre todo, Lobezno (Wolverine) que, como el prototipo griego de salvaje, rechaza la palabra y da importancia, básicamente, a sus instintos, que le permiten sobrevivir y convertirse, a menudo, en un cazador que se define por oposición al común de los mortales sedentarios. Tanto La Bestia como Lobezno son velludos, con garras y un aspecto montaraz, pero las variaciones iconográficas que ha suscitado Lobezno ostentan, además, una diversidad extraordinaria que resume la evolución del mito a lo largo del tiempo. Destacan, en ese sentido, aquellas imágenes en las que se ve a este personaje manipulado de manera artificial, para reforzar sus características brutales con un proceso de blindado metálico de su esqueleto, sobre todo en la versión dibujada por Barry Windsor-Smith Weapon-X (Marvel Comics Present \# 72-84, 1991). Acaso Lobezno, apresado para convertirse en un arma al servicio de intereses gubernamentales o privados expresa, mejor que ningún otro mutante, el miedo a perder la esencia humana por mor de la tecnología y, sobre todo, la necesidad de afrontar la idea del Otro después de la segunda Guerra Mundial, en plena Guerra Fría y bajo la amenaza nuclear ${ }^{10}$.

La densidad extraordinaria de la presencia del mito del salvaje en la Marvel ha alumbrado personajes que, como Calibán, apelan a las figuraciones literarias del salvaje. Al igual que el Calibán de La Tempestad (The Tempest, 1611), de Shakespeare, o que el Segismundo de La vida es sueño (1635), de Calderón de la Barca, a partir de los años setenta, los superhéroes adquieren consciencia de su diferencia y su animalidad y lo manifiestan a través de largos soliloquios y diálogos de corte melodramático y teatral. Tan autoconsciente es la propuesta, además, que existe un superhéroe llamado Calibán e historietas como Matarte para salvarte, de Los 4 Fantásticos, reproducen el asunto de La Tempestad, donde el individuo moderno nace cuando Próspero se salva a sí mismo de la tentación de convertirse en dios y acaba con Calibán ${ }^{11}$, una tensión también presente, por ejemplo, en el Ultimate Wolverine vs. Hulk(2005), de Lindelof - guionista también de las series Lost y The Leftovers-, Yu y McCraig.

Esta figura, a la vez heroica y anti-heroica del salvaje, fue llevada a sus lindes en los años ochenta, cuando guionistas como Frank Miller y Alan Moore decidieron retomar los viejos superhéroes e insuflarles una nueva dimensión trágica que se cifró, sobre todo, en la exacerbación de su condición salvaje como forma de actualizar una necesidad en otros tiempos satisfecha por los relatos mitológicos, las vidas de santos, la iconografía portátil o las truculentas historias de los cartelones de ciego. Batman, el regreso del señor de la noche, Elektra Assassin y Arkham Asyluym (Morrison \& McKean, 1989) exploran la posibilidad de utilizar personajes que no poseían, en principio, una dimensión salvaje tan marcada, y hacerles pasar por un período en que sus rasgos se acentúan, en este sentido, de una manera que acerca su descenso a los bosques interiores a un vía crucis o a la idea de una catábasis infernal. Gráficamente, este descenso se manifiesta en los héroes a través de un desarrollo hipertrófico de su musculatura, un completo abandono del aseo, una cons- 
tante laceración del cuerpo en condiciones penosas y un enfrentamiento a las condiciones más elementales de la subsistencia.

La furia y la melancolía se adueñan de ellos con la misma intensidad que lo podía hacer con los caballeros medievales de la vulgata artúrica, con personajes como Yvain. En torno a un personaje como Animal Man, que acarrea en sí mismo la capacidad de empatizar con las bestias (Morrison, 2011), podría hacerse una lectura muy directa, sobre todo en la singular reinvención del personaje realizada por Grant Morrison. Entre 1988 y 1989 - Animal Man, \#1 to \#26-, Morrison hizo de Animal Man un campo de operaciones para la exploración narrativa acerca de las potencialidades de la panopsis de la página y los universos holográficos de la física de Fritjof Capra $(1982,1998)$ o las teorías de la causalidad formativa de Rupert Sheldrake (1990a, 1990b, 1994), directamente invocadas a través de sus páginas, mientras sostenía a la par una elaboración del arquetipo animal. La fase finisecular del mito heroico, la que entronca con la escena narrada por Borges, corresponde a una extraña reconfiguración en la que se produce una fusión entre las potencias animales o teriomorfas y una muerte ha dejado de ser abandonada tras los pasos del héroe en forma de cuerpo residual o de coexistir con él como doble identidad para convertirse en su horizonte único.

Entreverada con el mecanismo del sueño, la presencia de esa muerte no vencida confiere a toda aventura, en el caso de Batman, Daredevil o Elektra, el cariz de un descenso órfico del salvaje. Ese es el caso de una de las criaturas recuperadas para la historieta de los ochenta por el guionista británico Alan Moore, La cosa del pantano (Swamp Thing) ${ }^{12}$, pero también de una criatura en apariencia tan diferente como el varias veces citado Dr. Manhattan. A diferencia de sus compañeros, que son héroes jubilados, el Dr. Manhattan no es sólo un enmascarado sino que está condenado a encarnar la alteridad porque es un mutante que no vive el tiempo cronológico sino que tiene la capacidad de habitar en todos los tiempos a la vez. Lejos de identificarse iconográficamente con un ser velludo y semianimal, es todo lo contrario, una entidad sutil que, como Estela plateada, el mesías por excelencia del universo Marvel que nació con los dibujos de Kirby y Buscema ${ }^{13}$, cobra una forma casi semitransparente y angélica, hasta el punto de ser representado con una transparencia que deja ver su sistema nervioso en las páginas que relatan su origen dentro de Watchmen. En el Dr. Manhattan cristaliza la idea de Bartra de que el salvaje constituye "una peligrosa grieta en el orden cósmico por donde puede derramarse el caos", precisamente por no acogerse a la habitual percepción social del tiempo. Si, según San Agustín, los monstruos son "un mensaje, una prueba de la fuerza divina sobre los cuerpos naturales, que prefigura el poder de Dios para provocar la resurrección final", el Dr. Manhattan constituye una amalgama del salvaje y el monstruo en la época contemporánea, en que el teocentrismo ha sido sustituido por la ciencia, y la cosmovisión centrada ligada a Dios por la relatividad de la física cuántica.

\section{El superhombre y la panopsis de la página}

"Helo aqui. Os mostraré al superhombre: es este relámpago. Es esta locura”. En un constante mirar al umbral doloroso en el que el superhombre emerge del hombre, la cita de Nietzsche permitió a Alan Moore delimitar el parpadeo que mediaba entre un viejo superhéroe británico casi olvidado de los años cincuenta, Marvelman (1954), escrito por Mick Anglo, y la resurrección que le fue encomendada en los ochenta, Miracleman (1985). Del mismo modo que Miracleman, arrancado de un ensueño de normalidad y obligado a contemplarse en su propia alteridad como superhéroe, todos los personajes de Moore son confrontados con una reinvención de lo humano que hunde sus raíces en la tradición shakesperiana y, precisamente por eso, los singulariza frente al conjunto de la heroarquía del cómic contemporáneo. La Cosa del pantano, el Dr. Manhattan de Watchmen y el protagonista de $V$ de Vendetta(1982-1988) han sido dotados con la capacidad de verse como personajes dramáticos y como artificios estéticos. Son, como ha señalado Harold Bloom (1994) acerca de Hamlet, Macbeth o Falstaff, libres artistas de sí mismos que se transforman en el acto de escuchar su propia voz, lo que los convierte en sujetos políticos en el orden de lo trágico.

A través de la voz, de un verbo que siempre es agente de cambio, Moore muestra su habilidad para evidenciar una auténtica psicología de la mutabilidad que arranca con La Cosa del pantano y culmina en la existencia plural y casi divina del Dr. Manhattan. La explicación científica, que hace de La Cosa una entidad botánica en perpetua separación de lo humano - "Creíamos que la cosa del pantano era Alec Holland transformado en planta. No lo era. jEra una planta que creía ser Alec Holland" - choca con su discurso poético: el lenguaje brota de la voz, y no la voz del lenguaje, y ante el "alguien habla" que precede al enunciado sólo puede 
aventurarse una cuestión ¿Cómo percibe el mundo La Cosa del pantano? ¿De dónde viene su palabra?, interrogante que se tensa en torno a secuencias como el largo diálogo que La Cosa sostiene con un cráneo humano. "¿Por qué cargo contigo si me tratas así?", interpela La Cosa a la calavera que descansa sobre sus manos nudosas. "Porque soy tu bumanidad", responde la quieta mandíbula. "Soy importante. Yo te mantengo en pie", dice, del mismo modo que la palabra irónica y falstaffiana de $\mathrm{V}$ mantiene en pie un último bastión de libertad e imaginación frente a la voz monocorde de la computadora Destino en $V$ de Vendetta.

Sin embargo, si la mentalidad mágica de Moore es capaz de otorgar una palabra formadora de mundo a la planta, al animal y al ser humano, en la frontera de lo suprahumano, el Dr. Manhattan, la única criatura con superpoderes de Watchmen, casi carece de palabra. Renacido del fuego, como el resto de personajes de Moore, y atrapado en un cuerpo imperecedero, es capaz de habitar a la vez en todos los tiempos y dimensiones. Auténtica metáfora de la panopsis de la página de historieta, de la presencia simultánea de las viñetas, el Dr. Manhattan, de quien se apropia el gobierno estadounidense en plena Guerra Fría para utilizarlo como arma en Vietnam, no tiene un anclaje que lo afiance al mundo. A diferencia de La Cosa, no hay en él una monstruosidad que lo anude a sus semejantes. En el límite de la extinción, su facies humana se revela como una cristalización de los motivos fundamentales del pensamiento y la narrativa de Moore: la negatividad del superhombre nietzscheano, la inminencia de un Apocalipsis inaplazable - "Dios, tú que nos has concedido una prórroga de tu Juicio Final”, rezan los personajes de $V$ de Vendetta-, la conciencia de un cambio de época, la obsesión conspirativa, el pensamiento complejo, la yuxtaposición de realidades y la identificación de patrones abstractos.

Atendiendo a esos patrones, relatos como Watchmen no se acomodan a una lógica lineal sino a grandes lineamientos o sincronicidades que van hilvanando los acontecimientos. A pesar de ser las únicas mentes preclaras - "es nuestra maldición, vemos todas las conexiones", anota un personaje secundario - el Dr. Manhattan, V, El Destripador en From Hell (1991-1996) o Moriarty en La liga de los caballeros extraordinarios (The League of Extraordinary Gentlemen, 1999-2019) constituyen, asimismo, la mancha opaca, el abismo en torno al que se constela el relato. Porque todos ellos desbordan el estatuto del monstruo, del freak, de la cosa y apuntan, a través del bagaje literario de Moore a la tensión siempre irresuelta que recae sobre el mutante contemporáneo. Por una parte, el mutante, como ha sido colegido de la pervivencia del salvaje, sigue siendo un nuevo avatar de "la cosa" entendida como la criatura que recorre la literatura de Mary Shelley, E. T. A. Hoffmann o Villiers de l'Isle-Adam, esto es el testimonio de una indagación sobre los límites de lo humano y su percepción con el que la literatura respondió en el siglo XIX a la revolución epistemológica del darwinismo y las ciencias biológicas y genéticas. Pero por otra parte, es también el testimonio de las cicatrices del siglo XX y de una profunda herida melancólica, entendida con Giorgio Agamben (1995), como proyección de la pérdida de lo que en realidad nunca se poseyó.

\section{La percepción posthumana}

Quizá a partir de una película en apariencia menor del ciclo de producciones de Marvel en la última veintena de años, El increíble Hulk (The Incredible Hulk 2008), de Louis Leterrier, es posible señalar la pregunta fundamental que, del Spiderman (2002) de Sam Raimi a la Fénix Oscura (Dark Phoenix, 2019), de Simon Kinberg, el mutante proyecta sobre el espectador ¿Cómo percibe el otro? ¿Cómo se presenta el mundo ante la percepción del mutante?, que a priori es la misma que, a través de Merleau-Ponty (1945) se podía aventurar sobre Frankenstein y otras criaturas del siglo XIX. El increíble Hulk comienza allí donde concluye el Hulk filmado por Ang Lee en 2003, en la invención de una nueva distancia entre el joven investigador Bruce Banner y su particular Mr. Hyde. La cifra bajo la que Stan Lee reinventó toda su pléyade de personajes heridos por la tragedia de la mutación, instauró, como se ha dicho, un nuevo modelo serial en el que las neurosis de la doble identidad, la encrucijada entre el cuerpo y la máscara del héroe aparecieron bajo el signo del melodrama. Pero si las preocupaciones sentimentales de Spiderman podían adquirir la forma visual de un rostro adolescente buscando su reflejo narcisista en el azogue acristalado de los rascacielos, el enorme cuerpo verde de Hulk siempre fue la mancha opaca de una monstruosidad condenada al silencio.

Desprovisto de palabra, Hulk no se enfrenta, como sus compañeros, a un mundo concebido como alteridad, sino que se mueve en el territorio abierto de lo animal (Agamben, 2006). Por eso, en la poderosa imagen de su silueta enfrentada a las potencias naturales, 
desafiando la tormenta y junto a una bella que acentúa su bestialidad, Louis Leterrier encuentra las raíces de una disponibilidad mitológica en la que King Kong, Frankenstein, el mencionado Calibán de La Tempestad, las sucesivas revisiones de La bella y la bestia y la obsesión por el control del Dr. Jeckyll quedan asociados a un imaginario de los elementos, que Hulk, a diferencia de los integrantes de Los 4 fantásticos puede asimilar pero no controlar. Las llamas de las que salva al personaje de Kate y la tierra de la que emerge para enfrentarse a su némesis, Blonsky, insuflan en este Hulk un peso que Ang Lee se había ocupado de sustraer. A la insistencia de Lee en las transiciones y cortinillas que le permitían librarse a la poética liviana de las viñetas, El increíble Hulk responde con una fluida continuidad de videojuego capaz de trocar los ensueños discontinuos en acción trepidante: desde las favelas brasileñas hasta el corazón de la Columbia Británica, Banner se ve llamado a fundar un nuevo Edén del que extirpar su propia monstruosidad y, con ella, los recuerdos, sueños y espejismos que jalonan la película de Lee: "Sólo conservo imágenes deshilvanadas, fragmentarias", asegura el protagonista después de cada uno de los trances que le convierten en Hulk.

Olvidada la figura amenazante del padre y el desierto en el que recibiera su primera dosis de rayos Gamma, la mutación de Bruce Banner se presenta como máquina o artificio en el que lo humano se desconoce y se conoce de manera sucesiva, siguiendo la idea de Kojève (1979) y Agamben (2006) de la necesidad que el género humano tiene de construirse máquinas de reconocimiento ante su imposible ubicación entre las otras especies animales. El homo sapiens no es ni una sustancia ni una especie claramente definida, sino, más bien, "una máquina o un artificio para producir el reconocimiento de lo humano" (Agamben, 2006, p.34), una máquina a la vez "antropológica” y "mitológica” (Jesi, 1977, 1979, 1980). Ante la pregunta “¿Cómo se revela el mundo para Hulk?” comparecen las imágenes antitéticas de los vastos horizontes que requieren sus gestos y la excesiva proximidad de lo minúsculo sobre lo que indaga Bruce Banner. Cultivos celulares, anfibios y holoturias desfilan bajo la óptica de un microscopio que, por oposición al espejo que suele acompañar a Spiderman o la multiplicación de universos del Dr. Manhattan de Watchmen, invocan una constante pero callada reescritura del código genético en el cuerpo metamórfico del superhéroe.

Cuando, en una de las secuencias de la película, el propio Stan Lee aparece sucumbiendo a la ingestión de una gota de la sangre contaminada de Hulk, promesa simultánea de convalecencia e inmortalidad, la tentación de adoptar el punto de vista de la enfermedad, de seguir el ejemplo del cineasta David Cronenberg, emerge por un instante para subrayar el universo escatológico de Marvel como una de las mejores figuraciones de la transformación de la política en lo que Foucault (2004) denominó biopolítica por parte del estado moderno. Al desdoblamiento, la doble identidad y la mutación, Marvel añadió, en los años noventa y, aún más con el 11-S, un constante contraplano que es el de la intervención no ya de los estados sobre el cuerpo sino la de las grandes corporaciones económicas. El despliegue militar en Irak y la merma de libertades de la administración Bush dieron forma al cross-over Civil War(2006) a través de las diferentes series de Marvel - con claras alusiones a las prisiones de Guantánamo y Abu Ghraib en las diferentes prisiones para mutantes - , del mismo modo que el descreimiento político contemporáneo sustenta esa especie de "tiempo del después" en el que desembocan tanto The Avengers: Endgame (2019), de Anthony y Joe Russo como Fénix Oscura.

De modo semejante a la pregunta que Agamben hace sobre la condición humana a partir de las investigaciones del biólogo Jakob von Uexküll sobre la percepción animal (Agamben, 2006), el interrogante esencial ya no es sólo ¿Cómo se revela el mundo para el mutante? sino ¿cómo la lógica del capital, el biopoder de los estados interviene sobre los cuerpos para modificar la sustancia misma de lo que define lo humano mientras reduce su potencial a una zoe capitalizable frente al bios dramático, singular, que había ostentado el mutante Marvel de los años setenta? Si la Guerra Fría permitió proyectar sobre los personajes de la Marvel la idea del Otro amenazante y el temor a perder la esencia humana por mor de la tecnología, a través de un mutante post-histórico como Hulk, como lo son todas las criaturas cinematográficas Marvel -incluso el súpergrupo más cercano a los universos mitológicos más conservadores de la DC: Los vengadores (The Avengers), en la tetralogía que se extiende desde The Avengers (2012), de Josh Whedon a The Avengers: Endgame-, el cuerpo humano aparece como un valor de venta que se disputan el ejército y las empresas privadas, un arma más sobre la que se invierte la iconografía que, desde la Edad Media, ha mostrado al simio, al salvaje, al freak y al engendro junto un espejo en el que el ser humano debía reconocerse como simia dei, como enfermedad mortal del animal, como un inquietante hiato entre el individuo y su potencial monstruosidad. 


\section{Epílogo}

"He pasado un tercio de mi vida en una cama de hospital, sin nada más que hacer que leer. He estudiado de manera intima la forma de los cómics. He visto los patrones en ellos... Las referencias a acontecimientos sociales y culturales y la atmósfera que los envuelve. He deducido que los cómics son nuestro último vínculo con una forma antigua de conocimiento. Los egipcios dibujaban imágenes en las paredes para narrar batallas y otros acontecimientos. En muchas culturas de todo el mundo todavia transmiten conocimiento a través de formas pictográficas. Creo que los cómics, incluso en la actualidad, preservan una verdad, describen lo que alguien, en algún lugar, sintió, experimentó...". Con estas palabras, Elijah Price, interpretado por el actor Samuel L. Jackson en el largometraje El protegido (Unbreakable, 2000) de Manoj Night Shyamalan, intenta sellar el vínculo profundo que le une al personaje protagonista, David Dunn (Bruce Willis), un hombre en apariencia común a quien Elijah ha ido atrayendo hacia su vida para verificar sus superpoderes y su extraordinaria resistencia física.

Con arreglo al trabajo del espacio fuera de campo desarrollado por M. Night Shyamalan en películas como El sexto sentido (The Sixth Sense, 1999), Señales(Signals, 2002), El bosque (The Village, 2004) o The Happening (2008), El protegido también arranca desde la contrafigura del héroe, el supervillano. Después de pasar la infancia leyendo cómics de superhéroes, Elijah, que padece de una osteogénesis imperfecta que le hace vulnerable y enfermizo, se obsesiona con que tiene que existir su contrario, alguien invulnerable, un superhéroe. Para encontrarlo, provoca una serie de aparatosos accidentes, uno de los cuales sólo deja con vida e indemne a David Dunn, lo que permite a Shyamalan centrarse en la fase narrativa menos sondeada del superhéroe, lo que estudioso del mito
Joseph Campbell denominó La negativa a la llamada en $E l$ héroe de las mil caras (1959). Cuanto en El protegido obedece a la representación de una búsqueda del héroe en el individuo común a través de largos planos secuencia fluidos, que casi contravienen la idea misma del cómic, aparece en Múltiple (Split, 2017) y Glass (2019) sometido a la construcción del héroe como figura post-política.

En efecto, la imagen recurrente de estas dos películas es la del superhéroe con una bata hospitalaria, dopado, adormilado, en una sala de control médico, sumido a veces en el tedio. Con su doble condición salvaje y posthumana, animal y tecnológica, el mutante constituye, siguiendo a Kojève (1979), Agamben (2006) y Jesi (1980), la plasmación de un individuo que ha alcanzado su telos histórico. Para una humanidad redevenida animal no queda otra alternativa, parecen sugerir esas imágenes, así como la trama conspirativa de control del superhéroe que apunta Glass, que la despolitización de la sociedad humana. Es en la figura del homo sacer agambeniano, consagrado por sus poderes y a la par excluido donde cabe ver la sorprendente afinidad iconográfica entre el Samuel L. Jackson postrado de Glass y Ventura, el emigrante caboverdiano protagonista de las últimas películas de Pedro Costa, en Cavalo Dinheiro (2014). En términos literales, la noción homo sacer, que Giorgio Agamben (2005) ha delimitado amparándose en la jurisprudencia romana define a aquel individuo juzgado por un delito, pero al que no es lícito sacrificar. Sin embargo, si alguien lo asesinara no sería condenado por homicidio ${ }^{14}$. La sacralidad del hombre sacro se presenta en su ambigüedad como residuo secularizado de una fase arcaica en la que el derecho religioso y el penal no estaban todavía diferenciados y la condena a muerte se presentaba como un sacrificio a la divinidad ${ }^{15}$, en este caso en una situación post-histórica no demasiado diferente a la que Borges anotaba en su cuento Ragnarök.

\section{Referencias}

Abrams, J. J. (creador). (2001). Alias [serie de televisión]. Estados Unidos: ABC, Bad Robot Productions.

Abrams, J. J., Lindelof, D., Burk, B., Higgins, J., Bender, J., Cuse, C., Kitsis, E., Horowitz, A., Sarnoff, E. (productores) y Abrams, J.J., Lindelof, D. (creadores). (2004). Lost [serie de televisión]. Estados Unidos: ABC, Bad Robot Production, Touchstone Television.

Abrams, J. J., Burk, B., Kurtzman, A., Orci, R., Wyman, J.H., Pinkner, J., Chapelle, J. (productores) y Abrams, J.J., Kurtzman, A., Orcid, R. (creadores). (2008). Fringe[serie de televisión]. Estados Unidos: Bad Robot Production, Warner Bros. Television.

Agamben, G. (1995). Estancias. La palabra y el fantasma en la cultura occidental. Valencia: Pre-Textos.

Agamben, G. (2005). Homo sacer. Il potere sovrano e la nuda vita. Torino: Einaudi.

Agamben, G. (2006). Lo abierto. Buenos Aires: Adriana Hidalgo.

Anglo, M. (1954). Marvelman \#1. Londres: L. Miller \& Son. 
Arad, A., Hurd, G. H., Feige, K. (productores), y Leterrier, L. (director). (2008). The Incredible Hulk [cinta cinematográfica]. Estados Unidos: Marvel Studios.

Bachelard, G. (1938). Psychanalyse du feu. París: Gallimard.

Bachelard, G. (1942). L'Eau et les rêves, París: Corti.

Bachelard, G. (1943). L'Air et les songes. París: Corti.

Bachelard, G. (1948a). La terre et les rêveries du repos: essai sur les images de l'intimité, París: Corti.

Bachelard, G. (1948b). La terre et les rêveries de la volonté, París: Corti.

Bartra, R. (1996). El salvaje en el espejo. Barcelona: Destino.

Bartra, R. (1997). El salvaje artificial. Barcelona: Destino.

Bloom, H. (1994). The Western Canon. The Books and School of the Ages. New York: Harcourt Brace \& Company.

Borges, J.L. (1960). El hacedor. Buenos Aires: Emecé.

Bryce, I., Ziskin, L. (productores) y Raimi, S. (director). (2002). Spiderman[cinta cinematográfica]. Estados Unidos: Marvel Entartainment-Columbia Pictures.

Brown, G., Cheramie, C. (productores) y Whedon, J., Tancharoen, M. (creadores). (2013). Agents of Shield [serie de televisión]. Estados Unidos: ABC, Marvel.

Burroughs, E. R. (1912). John Carter of Mars. A Prince of Mars. The All-Story Magazine. Nueva York: Frank A. Munsey Company. Calasso, R. (2006). K. Barcelona: Anagrama.

Campbell, J. (1959). El Héroe de las mil caras, psicoanálisis del mito. México: Fondo de Cultura Económica.

Campbell, J (2018). Imagen del mito. Vilaür: Atalanta.

Canetti, E. (1935). Die Blendung. Viena: Reichner.

Capra, F. (1982). The Turning point: science, society, and the rising culture. New York: Simon and Schuster.

Capra, F. (1998). La Trama de la vida: una nueva perspectiva de los sistemas vivos. Barcelona: Anagrama.

Claremont, Ch., Byrne, J., y Austin, Th. (1978-1979) G. The X-Men \# 115-117. Nueva York: Marvel Comics.

Claremont, Ch., y Windsor-Smith, B. (1985). X-Men Annual n 198. Lifedeath II: From the Heart of Darkness. Nueva York: Marvel Comics.

Claremont, Ch., y Windsor-Smith, B. (1987). Patrulla X Especial Primavera. Barcelona: Planeta de Agostini-Forum.

Claremont, Ch., Byrne, J., Austin, T.H. y Wein, G. (1990). Dark Phoenix. Nueva York: Marvel.

Claremont, Ch., Byrne, J., Austin, T.H. y Wein, G. (1992). La muerte de Fénix. La historia jamás contada. Barcelona: Planeta-Forum. Cole, J. (1941). Plastic Man. Police Comics \# 1. Quality Comics.

Conway, G., Kane, G., Romita Sr.J. Mortellaro, J., Hunt, D., (1973), The Night Gwen Stacy Died. Amazing Spider-Man \#121. Nueva York: Marvel Comics.

Damaso, R. (productor) y Costa, P. (director). (2014). Cavalo Dinheiro [cinta cinematográfica]. Portugal: Sociedad Óptica Técnica. Didi-Huberman, G. (1992). Ce que nous voyons, ce que nous regarde. París: Minuit.

Durand, G. (1960) Les structures anthropologiques de l'imaginaire. París, PUF.

Eisner, W. (1940), The Spirit \# 1. Estados Unidos: Register and Tribune Syndicate.

Eisner, W. (Davis, F.) y Mazoujian, Ch. (1940), Lady Luck \# 1. Estados Unidos: Register and Tribune Syndicate.

Falk, L. y Moore, R. (1936). The Phantom \#1. Estados Unidos: King Features Syndicate.

Feige, K. (productor) y Whedon, J. (director). (2012). The Avengers [cinta cinematográfica]. Estados Unidos: Marvel Studios, Walt Disney.

Feige, K. (productor), Russo, A. y Russo, J. (directores). (2019). The Avengers: Endgame [cinta cinematográfica]. Estados Unidos: Marvel Studios, Walt Disney.

Fine, A., Loeb, J., Quesada, J., Bucks, S., Goss, A., Lee, S., Buckley, D., Chory, J. (productores) y Buck, S. (creador). (2017). Iron Fist [serie de televisión]. Estados Unidos: Netflix, Marvel, ABC Studios.

Finger, B. y Kane, B. (1939). The Batman. The Case of the Chemical Syndicate. Detective Comics \# 27. Mayo 1939. California: Detective Comics Inc. 
Foucault, M. (2001). “L'incorporation de l'hôpital dans la technolo- gie moderne”, en: Dits et écrits, t. 2, París: Gallimard pp. $508-521$. Foucault, M. (2004). Naissance de la biopolitique, Cours au collège de France 1978-1979, Hautes études. París: Gallimard-Seuil. Fox, G. y Kane, B. (1939). The Batman. The Return of Dr. Death, Detective Comics \# 30. California: Detective Comics Inc. Frezza, G. (2017). La máquina del mito en el cine y el cómic. Madrid: Ediciones Marmotilla.

Frye, N. (1977). Anatomía de la crítica. Caracas: Monte Ávila Editores.

Gerosa, G. (1973). Presentazione. Edgar Rice Burroughs (comp.), John Carter, La principessa di Marte. 1. Firenze: Giunti-Marzocco. pp. 3-6.

Goss, A., Henigman, K., Holland, C., Fine, A., Goddard, D., Loeb, J., Quesada, G. Lee, S., Buckley, D., Chory, J., (productores) y Goddard, D. (creador). (2015). Daredevil [serie de televisión]. Estados Unidos: Netflix, Marvel, ABC Studios.

Gould, Ch. (1931). Dick Tracy. Estados Unidos: Chicago Tribune New York News Syndicate.

Grant, M (Gibson, W. B.). (1930). The Shadow. Serial radiofónico.

Hillman, J. (2016). Pan y la pesadilla. Vilaür: Atalanta.

Hodari Coker, Ch. (productor y creador). (2016). Luke Cage [serie de televisión]. Estados Unidos: Netflix, Marvel, ABC Studios.

Holland, C., Chory, J., Loeb, J., Lightfood, S., Goss, A., Delahaye, L., Henigman, K., Fine, A., Lee, S., Quesada, J., Zriek, K. (productores) y Lightfoot, S. (creador). (2017). The Punisher [serie de televisión]. Estados Unidos: Netflix, Marvel, ABC Studios.

Jeffery, S. (2016). The Posthuman Body in Superhero Comics. Human, Superhuman, Transhuman, Post/Human. New York: Palgrave-Macmillan.

Jesi, F. (1977). “Conoscibilita della festa”. En: La festa. Antropologia, etnología, floclore. Turín: Rosenberg \& Sellier.

Jesi, F. (1979). “La festa e la macchina mitológica”. En Materiali mitologici. Mito e antropología nel/a cultura mitteleuropea. Torino: Einaudi.

Jesi, F. (1980). “La macchina mitologica: ideología e mito”. En Mito. Milano: Arnoldo Mondadori Editore.

Kingsley, P. (2008). Filosofía antigua, misterios y magia. Empédocles y la tradición pitagórica. Vilaür: Atalanta.

Kingsley, P. (2017). En los oscuros lugares del saber. Vilaür: Atalanta.

Kojève, A. (1979). Introduction à la lecture de Hegel. Paris: Gallimard.

Kring, T. (productor y creador). (2006). Heroes [serie de televisión]. Estados Unidos: Universal Television, NBC.

Lacofano, T., (productor) y Rosenberg, M. (creador). (2015). Jessica Jones[serie de televisión]. Estados Unidos: Netflix, Marvel, ABC Studios.

Lee, S., Kirby, J., Klein, G., y Rule, Ch. (1961). The Fantastic Four \# 1. Nueva York: Marvel Comics.

Lee, S., Kirby, J. y Colletta, V. (1965). The Fantastic Four \# 42, \# 43. Nueva York: Marvel Comics.

Lee, S. y Kirby, J. (1966) The Fantastic Four. The Galactus Trilogy. \# 48, 49, 50. Nueva York: Marvel Comics. [(1990). Clásicos Marvel $n^{\circ}$ 18. Barcelona: Planeta de Agostini-Forum].

Lee, S., Kirby, J. y Colletta, V. (1969). Los 4 fantásticos n² 21. Barcelona: Ediciones Vértice.

Lee, S. y Moebius. (1988-1989). Parable \#1, \#2. Nueva York:w Marvel Comics.

Leslie Parker, B. (productor) y Hawley, N. (creador). (2017). Legion [serie de televisión]. Estados Unidos: FX, Marvel, 20th Television.

Lindelof, D., Yu, L. F. y McCraig, D. (2005). Ultimate Wolverine vs. Hulk. Nueva York: Marvel Comics.

Lindelof, D., Perrotta, T., Berg, P., Aubrey, S. (productores) y Perrota, T., Lindelof, D. (creadores). (2014). The Leftovers [serie de televisión]. Estados Unidos: HBO, Warner Bros Television.

Magris, C. (1993). El anillo de Clarisse. Tradición y nibilismo en la literatura moderna. Barcelona.

Marshall, F., Kennedy, K., Mendel, B. (productores) y Shyamalan, M. N., (director). (1999). The Sixth Sense [cinta cinematográfica]. Estados Unidos: Spyglass Entartainment, The Kennedy Marshall Company, Hollywood Pictures, Buena Vista Pictures.

Merleau-Ponty, M. (1945). Phénoménologie de la perception. Paris, Gallimard [Fenomenología de la percepción, Barcelona: Planeta, 1993].

Millar, M., Mc.Niven, S., Vines, S. y Hollowell, M. (2006) Civil War I-VII. Nueva York: Marvel Comics.

Miller, F. (1986). Batman Dark Knight. California: DC Comics.

Miller, F. y Sienkiewicz, B. (1986). Elektra Assassin I-VIII. Nueva York: Marvel Comics. 
Moebius (1989). Entrevista "Surfer d'Argent", realizada por Numa Sadoul. Les cabiers de la bande dessinée, n 86, septiembre de 1989. Grenoble: Glénat, pp.46-59.

Moore, A. y Lloyd, D. (1982-1988). V de Vendetta, in Warrior 1982-1985. London: Quality Communications; (1988) California: DC Comics.

Moore, A., Day, D., Totleben, J., Wood, T. (1984). The Saga of the Swamp Thing. Swamp Thing, vol2 \#20. California: DC Comics. Moore, A., Leach, G., Davis, A., Austen, Ch., Veitch, R. y Totleben, J. (1985). Miracleman. California: Eclipse Comics.

Moore, A. y Gibbons, D. (1986). Watchmen I-XII. California: DC Comics.

Moore, A. From Hell (1988-1996). Taboo, \# 2-7, Spyderbaby Graphix. Tundra Publishing (1988-1992). Tundra Publishing y Kitchen Sink Press (1992-1996).

Moore, A. y O’Neill, K. (1999-2019) The League of Extraordinary Gentlemen, I, II, III, IV. California: DC Comics-America’s Best Comics.

Morrison, G., Truog, Ch., et al. (1988-1990), Animal Man. \#1 to \#26. California: DC Comics.

Morrison, G. y McKean, D. (1989). Arkham Asyluym. California: DC Comics.

Morrison, G. (2011). Supergods. New York: Penguin Random House.

Nowlan, Ph. y Calkins, D. (1933). Buck Rogers. Daily Strip. Estados Unidos: diversas editoriales.

Panofsky, E. (1982). Estudios sobre iconología. Madrid, Alianza.

Pintor, I. (2015a). "Dream and History, the Cartoon Mirror: the Incorporation of History into the Comic Book”, en Esther Claudio y Julio Cañero, ed. On the Edge of the Panel. Essays on Comics Criticism. Cambridge: Cambridge Scholars.

Pintor, I. (2015b). "L'intervallo allucinatorio nelle avventure di Corto Maltese, di Hugo Pratt: La figurazione della parola e la discontinuità visiva”. H-ermes. Journal of Communication, 6: 31-58.

Pintor, I. (2017). Figuras del cómic. Forma, tiempo y narración secuencial. Barcelona, Valencia: Universitat Autònoma de Barcelona, Universitat Jaume I, Universitat Pompeu Fabra, Universitat de València (Aldea Global, 37).

Pintor, I. (2018). "O Somma Luce. Otherwordly journeys and encounters with the Goddess. A comparative approach of the Dantean beritage in the comic books of Hugo Pratt, Fellini and Manara and Makyo". Dante e l'Arte. Vol. V. 2018, pp. 11-36. ISSN 2385-5355 (digital) • ISSN 2385-7269 (paper) Recuperado de: http://revistes.uab.cat/dea

Raymond, A. (1934). Flash Gordon. Sunday Strip. Estados Unidos: King Features Syndicate.

Schneider, M. (1998). El origen musical de los animales-simbolos en la mitología y la escultura antiguas. Ensayo histórico-etnográfico sobre la subestructura totemistica y megalítica de las altas culturas y su supervivencia en el folklore español. Madrid: Siruela.

Sheldrake, R. (1990b). La presencia del pasado: resonancia mórfica y hábitos de la naturaleza. Barcelona: Kairós.

Sheldrake, R. (1990b). Una nueva ciencia de la vida: la hipótesis de causación formativa. Barcelona: Kairós.

Sheldrake, R. (1994). El renacimiento de la naturaleza: el resurgimiento de la ciencia y de Dios. Barcelona: Paidós.

Shuler Donner, L.,Kinberg, S., Singer, B. (productores) y Kinberg, S. (director). (2019). Dark Phoenix [cinta cinematográfica]. Estados Unidos: Marvel Entartainment, 20th Century Fox, Walt Disney.

Shyamalan, M. N., Mendel, B., Mercer, S. (productores) y Shyamalan, M. N., (director). (2000). Unbreakable [cinta cinematográfica]. Estados Unidos: Touchstone Pictures, Blinding Edege Pictures, Barry Mendel Productions, Limited Edition Productions Inc., Buena Vista Pictures.

Shyamalan, M. N., Marshall, F., Mercer, S. (productores) y Shyamalan, M. N., (director). (2002). Signals [cinta cinematográfica]. Estados Unidos: Touchstone Pictures, Blinding Edge Pictures, The Kennedy Marshall Company, Buena Vista Pictures.

Shyamalan, M. N., Mercer, S., Rudin, S. (productores) y Shyamalan, M. N., (director). (2004). The Village [cinta cinematográfica]. Estados Unidos: Touchstone Pictures, Blinding Edge Pictures.

Shyamalan, M. N., Mercer, S., Mendel, B. (productores) y Shyamalan, M. N., (director). (2007). The Happening [cinta cinematográfica]. Estados Unidos: Spyglass Entartainment, Blinding Edge Pictures, UTV Motion Pictures, 20th Century Fox.

Shyamalan, M. N., Bienstock, M., Blum, J. (productores) y Shyamalan, M. N., (director). (2016). Split [cinta cinematográfica]. Estados Unidos: Blinding Edge Pictures, Universal Pictures.

Shyamalan, M. N., Blum, J. (productores) y Shyamalan, M. N., (director). (2019). Glass [cinta cinematográfica]. Estados Unidos: Blinding Edge Pictures, Blumhouse Productions, Universal Studios, Walt Disney Studios Motion Pictures, Touchstone Pictures.

Windsor-Smith, B. (1991). Weapon-X (Marvel Comics Present \# 72-84). Nueva York: Marvel Comics. 
Frezza desarrolla la apreciación de Guido Gerosa (1973), que subrayó en 1973 una extraordinaria parentela entre el personaje literario de John Carter de Marte, protagonista del ciclo marciano de Edgar Rice Burroughs, y los héroes de los cómics de aventuras: Buck Rogers, Brick Bradford y Flash Gordon.

2 La distinción entre la imagen - imago - y el vestigium, esto es la ruina, la huella, el vestigio, entre algunos teólogos de la Edad Media aludía a la idea de que todo lo que es visible acarrea siempre la huella de una semejanza perdida. Véase: Didi-Huberman, G. (1992). Ce que nous voyons, ce que nous regarde, p. 14. París: Minuit.

3 Dentro de la mitología Marvel, resulta particularmente interesante esta constelación de personajes: Rayo Negro, su esposa Medusa, Crystal, Gorgón, Karnak y Tritón encarnan la otredad hasta el extremo de ser la familia real de una especie que convive, en una dimensión paralela, con los humanos, y que contiene la semilla de los universos paralelos de series como Fringe, de J. J. Abrams.

4 Cíclope, Fénix, Coloso o Night Crawler (Rondador nocturno) pertenecen, de modo más o menos intermitente, al grupo de los $X$-Men. Fénix se incorporó más tarde, y destaca en ese sentido la saga de episodios que fue dedicada a este personaje en los años ochenta, con guión de Chris Claremont y dibujos de John Byrne. Existe una edición en Paperback de esta saga, (1990). Parte de ella ha sido publicada en castellano en La muerte de Fénix. La historia jamás contada. Barcelona: Planeta-Forum, 1992, y es la base narrativa del filme de Simon Kinberg, con guión de Claremont y Byrne X-Men: Fénix Oscura (Dark Phoenix, 2019).

5 Existe, de hecho, un bello episodio con guión de Chris Claremont y dibujos de Bary Windsor-Smith que relata el paso de Tormenta por el desierto africano y una serie de episodios mitológicos como el encuentro con la serpiente y las fuerzas naturales, que preceden a su iniciación como heroína. Véase X-Men Annual no 198 (En castellano en: Patrulla X Especial Primavera. Barcelona: Planeta de Agostini-Forum, 1987).

6 Este es el término que utiliza Durand (1960) para referirse a los simbolismos de la amenaza animal.

$7 \quad$ Personaje que en realidad adopta las facultades multiplicadas de una avispa y viste de un modo acorde. Ha aparecido en varias series, pero sobre todo enfrentándose a Los Vengadores. Véase The Avengers 213-214 ( New York: Marvel, 1981. Edición en castellano en Los Vengadores no 28, 1985. Barcelona: Planeta de Agostini-Forum, 1985).

8 Aparece, por ejemplo, en los episodios del nuevo Namor realizados por John Byrne, publicados en España en la miniserie Namor (Barcelona: Planeta de Agostini, 1990).

9 Corresponde, como Panofsky ha señalado al hablar de la iconografía renacentista, al Padre Cronos, el devorador, el objeto último del enfrentamiento del héroe. Véase el capítulo tercero de Estudios sobre iconología, titulado "El padre Tiempo" (1982: 93-139).

10 Entre las innumerables historietas de Lobezno y el resto de mutantes Marvel, destacan los episodios de los $X$-Men en que el equipo de superhéroes se desplaza la llamada “Tierra Salvaje” (The X-Men \# 115-117, 1978-1979), donde se enfrentan a los sucesos que tienen lugar en una especie de tierra imaginaria donde habita una humanidad paralela.

11 Los 4 fantásticos n 21. Ediciones Vértice, 1969 (Fantastic Four Vol.1 \#42 \#43 Edición USA).

12 En La cosa del pantano, la musculatura y el vello adquieren un nuevo estatuto, todavía más primitivo, pues ambos son sustituidos por una capa de musgo y plantas epifitas que le crecen encima, como en los disfraces que en ciertas culturas celebran al hombre salvaje. Su aspecto provoca un rechazo en la sociedad, y su natural bondad se ve obligada, como en el caso de Frankenstein, a un choque con la realidad que le conduce a comportarse de un modo violento, irascible y primitivo. No es casual que el dibujante Bernie Wrightson se haya ocupado tanto de La Cosa del pantano como de Frankenstein. El interés de Moore con su entrada a partir del vol2 \#20 (1984) es, justamente, recoger de un modo verista las dificultades que tendría una criatura así en el mundo contemporáneo, y algunas de las imágenes que le muestran acorralados por policías y perros exhiben un curioso paralelo con lo que postula Roger Bartra en el cierre de El salvaje en el espejo (1997) acerca de un grabado en el que un hombre salvaje es rodeado por perros domesticados: no se sabe si lucha por escapar de la naturaleza o de la civilización.

13 El nacimiento de Estela Plateada fue relatado en The Fantastic Four n ${ }^{\circ}$ 48, 49, 50 (1966. Versión castellana en Clásicos Marvel no 18. Barcelona: Planeta de Agostini-Forum, 1990. El Silver Surfer encuentra su más ajustada configuración en el dibujo de un artista ajeno al ámbito de los superhéroes, Moebius, en Parábola (Parable, 1989). En la edición española de Parábola (Barcelona: Planeta, 1989) pueden encontrarse sendos textos de Stan Lee y Moebius sobre la obra. Además, Numa Sadoul realizó una larga entrevista sobre esta obra a Moebius en Les cabiers de la bande dessinée, nº 86 (1989).

14 "Infatti nella prima legge tribunizia si avverte che 'se qualcuno ucciderà coluì che per plebiscito è sacro, non sarà considerato omicida'; Sacra è la nuda vita uccidibile e non sacrificabile, sottostante al potere sovrano. Questo ambito ambivalente è il luogo di azione del politico, o della giustizia umana [né violenzaanimale, né giustizia divina]” (Agamben, 2005, p. 94).

15 "A questo punto non sembra fuor di luogo trattare della condizione di quelli uomini che la legge comanda essere sacri a certe divinità, poiche non ignorano che a certuni appare strano che, mentre è vietato violare qualsiasi cosa sacra, sia invece lecito uccidere l’uomo sacro", escribía ya Macrobio Apud. (Agamben, 2005, p. 95). 